\title{
SPH Modeling of Surge Overflow over RCC Strengthened Levee
}

\author{
Lin $\mathrm{Li}^{1}$, Farshad Amini ${ }^{*}$, Xin Rao ${ }^{2}$ and Hongwu Tang ${ }^{2}$ \\ ${ }^{1}$ Department of Civil and Environmental Engineering, Jackson State University, Jackson, Mississippi, 39217, USA \\ ${ }^{2}$ State Key Laboratory of Hydrology-Water Resources and Hydraulic Engineering, Hohai University, Nanjing, China, 210098
}

(Manuscript Received October 4 2012; Revised November 2, 2012; Accepted November 29, 2012)

\begin{abstract}
Surge overflow may cause damage on earthen levees. Levee strengthened on the levee crest and landward-side slope can provide protection against the erosion damage induced by surge overflow. In this paper, surge overflow of a roller compacted concrete RCC strengthened levee was studied in a purely Lagrangian and meshless approach, the smoothed particle hydrodynamics (SPH) method. After verifying the developed model with analytical solution and comparing the results with full-scale experimental data, the roughness and erosion parameters were calibrated. The water thickness, flow velocity, and erosion depth at crest, landward-side slope and toe were calculated. The characteristics of flow hydraulics and erosion on the RCC strengthened levee are given. The results indicate that the RCC strengthened levee can resist erosion damage for a long period.
\end{abstract}

Keywords: SPH method, Surge Overflow, Roller compacted concrete, Levee, Erosion

\section{Introduction}

Earthen levees are used extensively in the United States to protect populations and infrastructure from periodic floods and high water due to storm surges. When the surge level exceeds the levee crest elevation without accompanying wave action, surge only overflow/overtopping occurs and produces fastflowing water on the landward-side slope that can damage the protective covering and expose the underlying soil to erosion. Post-Katrina investigations showed that during overtopping, the landward-side of levees was exposed to significantly higher velocities and much greater erosive forces than the flood side [1]. Protecting earthen levees from erosion by surge overflow is necessary to assure a viable and safe levee system [2]. Roller compacted concrete (RCC) is one of the levee strengthening methods to resist erosion damage $[3,4]$.

\footnotetext{
${ }^{*}$ Corresponding author. Tel.: +1 601 9793913, Fax.: +1 60109793238 , E-mail address: famini@jsums.edu Copyright $(C)$ KSOE 2012.
}

RCC is a combination of sand and gravel having a controlled gradation to which cementing materials such as cement and pozzolan are added. The controlled-gradation stone aggregate contains the nominal maximum size aggregate averaging about $38 \mathrm{~mm}$. The materials are blended with water to damp consistency that can be hauled in vehicles or delivered with a conveyor, spread with earth-moving equipment in layers, and compacted with a steel-drum vibratory roller [5]. Due to its simplicity, RCC has been used in dam construction and modification and has potential applications for use in protection against overtopping of levees [6,7].

A full-scale study on surge overflow and combined wave and surge overtopping of a levee strengthened with RCC was conducted in the Large Wave Flume. The hydraulic data (discharge, water velocity and flow thickness) and erosion depth were obtained. Based on the measured flow thickness and flow velocity on the crest and the landward-side slope, new equations were developed to estimate the distribution of instantaneous discharge, flow parameters on the 
landward-side slope, e.g. mean flow thickness, mean velocity, and velocity of the wave front [8].

Levee breach problems are often numerically solved using Eulerian approaches such as the finite volume method or finite element method. Since the levee breach usually occurs under wave condition and as a result of wetting-drying flood phenomena, the smoothed particle hydrodynamics (SPH) method is more appropriate $[9,10,11,12,13,14,15]$. The $\mathrm{SPH}$ method is a gridless, pure Lagrangian method for solving the equations of fluid dynamics. In this approach, the particles are calculated through the interactions with the neighboring particles using an analytical kernel function. All terms in the governing equations can be represented by the particle interaction models. Grid is not needed because renormalizations techniques rely on background grids [16,17]. These features of the SPH are very useful for a two-phase flow with water-structure interactions. Khayyer et al. [18] used corrected incompressible SPH method to simulate the breaking and post-breaking of solitary waves on a plane slope. Dalrymple and Rogers [19] demonstrated the SPH method in modeling breaking waves on beaches in two and three dimensions, green water overtopping of decks, and wave - structure interaction. Rao et al. [15] used the SPH method to simulate the combined wave and surge overtopping and hydraulic erosion of a levee embankment strengthened by articulated concrete block system.

In this paper, the SPH method is used to study surge overflow on a RCC strengthened levee. After verifying the SPH model with full scale experiment hydraulic and erosion results, the characteristics of overflow hydraulics and erosion rate on the levee crest, landward-side slope and toe are provided.

\section{Methodology}

\subsection{Governing Equation}

Shallow water equation can be written as:

$\mathrm{h}\left(\frac{D \vec{u}}{D t}+\frac{\nabla P}{\rho}\right)=-g h \nabla z-g u^{2} / c^{2}$

where $u$ is the velocity and $p$ is the pressure, $z$ is the landform elevation, $h$ is the water depth, $c$ is the Chezy coefficient. The Chezy coefficient is calculated by following equation:
$c=R^{1 / 6} / n$

where $R$ is the hydraulic radius, $\mathrm{n}$ is the Manning coefficient.

For a particle $i$, the nodal acceleration is written in particle form [20]:

$$
\begin{gathered}
\frac{D \vec{u}_{i}}{D t}=-\sum_{j=1}^{N} m_{j}\left(\frac{P_{j}}{\rho_{j}^{2}}+\frac{P_{i}}{\rho_{i}^{2}}\right) \nabla w\left(x_{i}-x_{j}\right)-\sum_{j=1}^{N} v_{j} g z \nabla w\left(x_{i}-x_{j}\right) \\
-\sum_{j=1}^{N} v_{j} g u_{j}{ }_{j}^{2} n^{2} w\left(x_{i}-x_{j}\right) / h^{4 / 3}
\end{gathered}
$$

where $u_{i}$ is velocity of particle, $\rho_{i}$ is density of the particle, $P_{j}$ is pressure at the particle, $m_{j}$ is mass of the particle $j$. In order to avoid interpenetration of particles, an artificial viscosity was proposed by Monaghan [20] and is given by

$\Pi_{i j}= \begin{cases}-\alpha_{i j} \mu_{i j}+\beta \widetilde{c}_{i j} u_{i j}^{2} & \left(u_{i}-u_{j}\right)\left(x_{i}-x_{j}\right)<0 \\ 0 & \text { elsewhere }\end{cases}$

where $\alpha$ and $\beta$ are constants, respectively, taken as 0.01 and 0.1 in this study. $\widetilde{c}_{i j}=\left(\sqrt{g h_{i}}+\sqrt{g h_{j}}\right) / 2$ and $u_{i j}=l \cdot\left(u_{i}-u_{j}\right) \cdot\left(x_{i}-x_{j}\right) /\left(\gamma_{i j}^{2}+0.01 h^{2}\right), l$ is the smoothing length, $r_{i j}$ is the distance between particles $i$ and $j$. Thus, the stabilized discrete momentum equations become:

$$
\begin{gathered}
\frac{D \bar{u}_{i}}{D t}=-\sum_{j=1}^{N} V_{j}\left(g\left(h_{j}+h_{i}\right)+\Pi_{i j}\right) \nabla w\left(x_{i}-x_{j}\right)-\sum_{j=1}^{N} v_{j} g z_{j} \nabla w\left(x_{i}-x_{j}\right)(5) \\
-\sum_{j=1}^{N} v_{j} g u_{j}{ }_{j}^{2} n^{2} w\left(x_{i}-x_{j}\right) / h^{4 / 3}
\end{gathered}
$$

Shear stress for the erosion process can be obtained as [21]:

$$
\tau=k \theta^{n}
$$

where $\tau$ is the shear stress, $k$ is the shear stress constant, taken as 1.0. $\theta$ is the shear rate and $n$ is the flow behavior index, taken as 0.5 .

The shear rate can be approximated as:

$\theta=v_{r e l} / l_{r e l}$ 
where $l_{r e l}$ is the distance between flow particle and landform particle. $v_{\text {rel }}$ is the relative velocity between flow particle and landform particle.

The erosion rate $\varepsilon$ is formulated as:

$\varepsilon=k_{\varepsilon}\left(\tau-\tau_{c}\right)$

where $k_{\varepsilon}$ is the erosion strength and $\tau_{c}$ is the critical shear stress. When $l_{r e l}$ is less than smoothing length and $\tau$ is greater than $\tau_{c}$, erosion happens.

The SPH discrete form of mass change is expressed as [21]:

$d M_{i} / d t=-\sum_{j} l^{2} \varepsilon(j)$

where $M_{i}$ is the mass of landform particle. When erosion happens, the mass and the volume of the boundary particles decrease. The profile of the slope changes due to the decrease in volume of the particles. The particle is then removed from the domain until the mass decreases to zero.

\subsection{Conceptual Model}

The conceptual model of levee embankment strengthened by RCC on the crest and landwardside slope is shown in Fig. 1a. The width of the levee crest along the flow direction is $2 \mathrm{~m}$. The landward-side has a slope of $1 \mathrm{~V}: 3 \mathrm{H}$. The crest and landward-side slope were divided into 809 fixed column particles (boundary particles, no velocity). Each particle has its own properties of mass, height, and volume. Flow particles were initially assigned in the far upstream of the levee embankment, as indicated in Fig. 1b. The surge overflow depth in the upstream was assumed to be constant in the simulation, after achieving steady-state surge overflow condition.

\subsection{Boundary treatment}

One of major boundary treatment methods in SPH is ghost particle technique [22]. The principle of dealing with boundary is by making the kernel to have a compact support, i.e., full of particles in the smoothing circle. Near the boundary, the kernel does not have complete smoothing circle. Symmetrical ghost particles needed to be added to make the smoothing circle completely full. Depending on the boundary conditions, ghost particles were assigned with different properties in velocity, mass, and volume. In this study, negative water depth and velocity of real particles were used for the ghost particles to keep the pressure and velocity of the boundary equal to zero.

\subsection{RCC strengthening layer treatment}

In the Eq. 5, the influence of the boundary surface is shown as $\sum_{\mathrm{j}=1}^{\mathrm{N}} \mathrm{v}_{\mathrm{j}} \mathrm{gu}_{\mathrm{j}}{ }^{2} \mathrm{n}^{2} \mathrm{w}\left(\mathrm{x}_{\mathrm{i}}-\mathrm{x}_{\mathrm{j}}\right) / \mathrm{h}^{4 / 3}$. The Manning roughness coefficient $n$ is used to calculate this item. The roughness $\mathrm{n}$ can represent the material feature of RCC strengthening layer. In this paper, an initial roughness (0.015) was given to simulate the hydraulic process of surge overflow through the strengthened levee. After calibrating with the full-scale overflow test results, the calibrated roughness can be obtained.

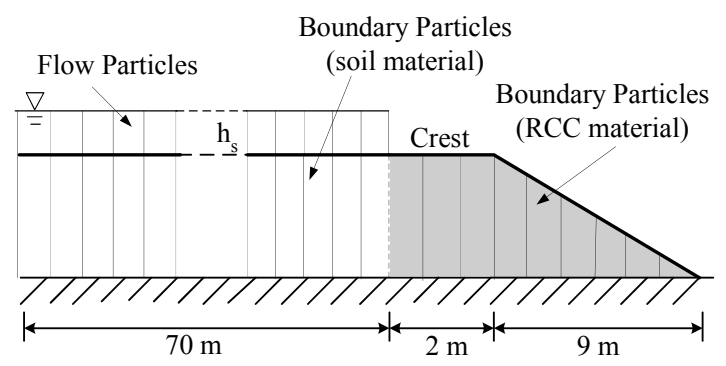

(b)

Fig. 1. Conceptual setup of earthen levee strengthened by RCC on the crest and landward-side slope under surge overflow (a). Freeboard $h_{s}$ is defined as vertical distance between the still water elevation and crest elevation. Initial condition of particles setup (b). 


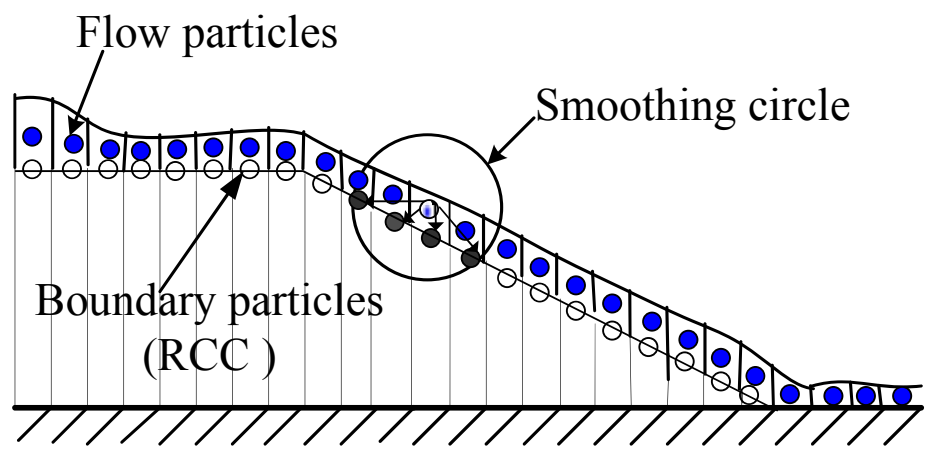

Fig. 2. Illustration of erosion process in the ghost particles method.

\subsection{Erosion Simulation}

As shown in Fig. 2, when the boundary particles are in the smoothing circle of the flow particles, the flow particles would give shear stress to the boundary particles. If the shear stress is above the critical value, erosion occurs. The mass change of solid boundary particles in the solid boundary is used to represent the erosion in every time step. The decreased value is the eroded mass. Once they are fully eroded, it is removed from the simulation.

In the SPH method, the distance among the particles varies in time. At each time step, the nearest neighboring particles for every specified particle have to be found. Linked-list algorithm was used due to its effectiveness and being relatively easy to implement [22].

\section{Model Calibration and Verification}

\subsection{Verification for earthen Levee}

In the steady water overflow of a levee, subcritical flow exists on the high-water side of the levee. If the horizontal levee crest is sufficiently long to

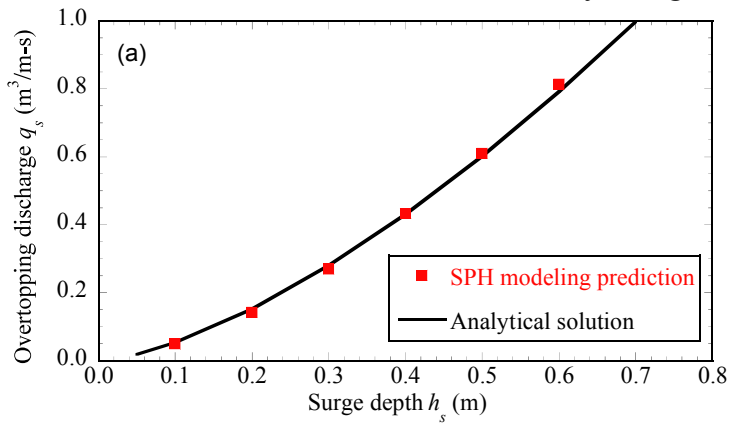

maintain a hydrostatic pressure distribution, critical flow (transition between subcritical and supercritical flow) occurs somewhere along the levee crest, and the flow down the landward-side slope is supercritical. Assuming minimal frictional energy losses along the crest, the discharge per unit length of levee can be calculated by the equation for flow over a broad-crested weir in open channel flow [23] as Eq. 10.

$q_{s}=(2 / 3)^{3 / 2} \sqrt{g} h_{s}^{3 / 2}$

where $q_{s}$ is the steady overflow discharge per unit length in $\mathrm{m}^{3} / \mathrm{s}-\mathrm{m}$, and $h_{s}$ is the surge overflow depth in $\mathrm{m}$ (difference between surge elevation and levee crest elevation).

Supercritical flow down the landward-side levee slope can be estimated using the Manning equation. At some point down the slope, a balance is reached between the water momentum and the frictional resistance of the slope, and the flow becomes steady. The steady flow velocity can be estimated by Eq. (11).

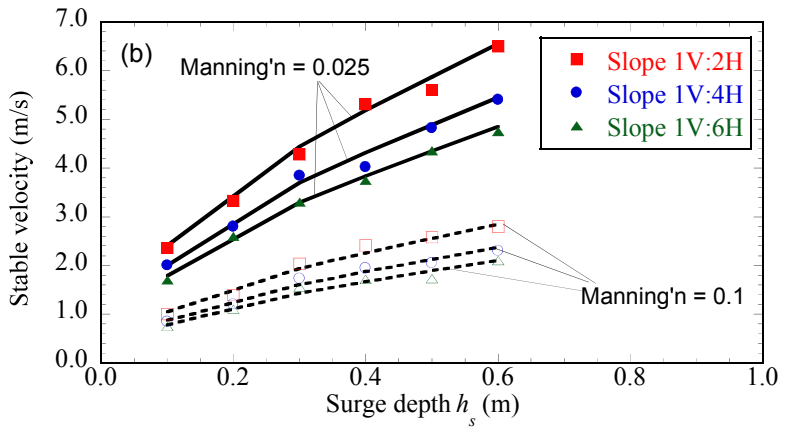

Fig. 3. Model verification with analytical solution: (a) overtopping discharge, and (b) stable velocity in landward-side slope. 
$v_{0}=\left[\frac{\sqrt{\sin \theta}}{n}\right]^{3 / 5} q_{0}^{2 / 5}$

where $v_{0}$ is the steady flow velocity in $\mathrm{m} / \mathrm{s}, n$ is the Manning coefficient, $\theta$ is landward-side levee slope, and $q_{0}$ is steady critical discharge in $\mathrm{m}^{3} / \mathrm{s}-\mathrm{m}$.

Fig. 3a shows the comparison between Eq. (10) and the SPH predicted surge overtopping discharge as a function of surge depth. The SPH predication compares well with the analytical solution. Fig. 3b shows a comparison between Eq. (11) and SPH predicted stable velocity along the landward-side slope at the different Manning coefficients and slopes. For the three landward-side slopes, and the two Manning coefficients, the SPH predications agree well with the analytical solution.

\subsection{Verification for RCC Strengthened Levee}

Since there is no Manning roughness coefficient $\mathrm{n}$ in the literature for RCC strengthened levee, the experimental results in $\mathrm{Li}$ et al. [8] was used to calibrate the coefficient. From the full-scale overtopping experiment, the average flow velocity at the middle of levee crest was $1.6 \mathrm{~m} / \mathrm{s}$ in surge overflow condition with a surge height of $0.3 \mathrm{~m}$. The Manning roughness coefficient $\mathrm{n}$ was calibrated in $\mathrm{SPH}$ model to compare the flow velocity at the middle of levee crest with the measured data. Fig. 4a shows the calculated steady-state velocity at the middle of crest as a function of roughness coefficient $n$ for an overflow depth $h_{s}$ of $0.3 \mathrm{~m}$. The calibrated roughness coefficient $\mathrm{n}$ for the RCC is 0.02 .
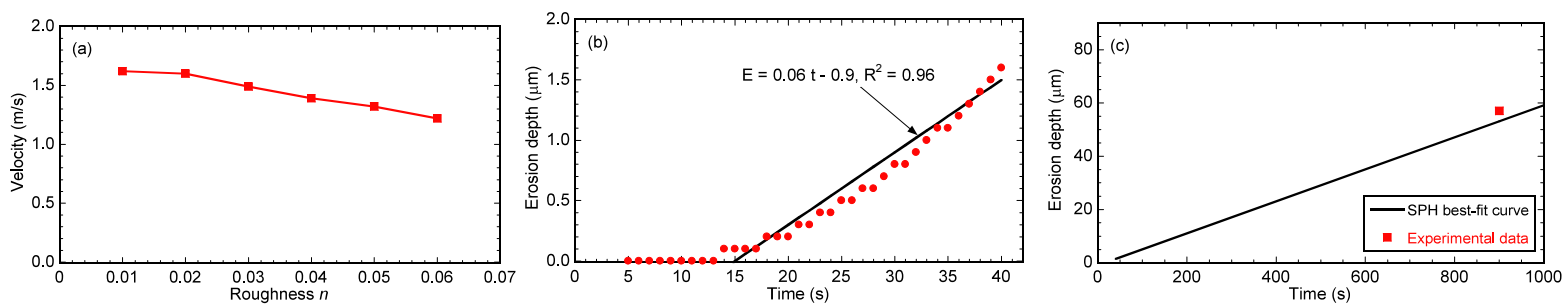

Fig. 4. Model calibration for roughness $\mathrm{n}$ with experimental data on the middle of the crest: (a) velocity, (b) SPH prediction of erosion trend, and (c) erosion comparison.

(a) Time $t=1.0 \mathrm{~s}$

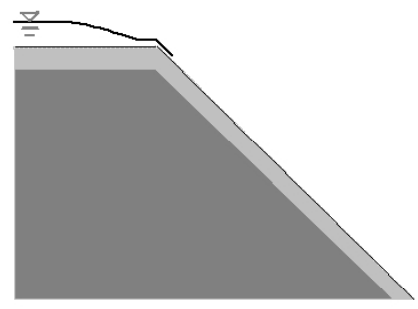

(c) Time $t=3.0 \mathrm{~s}$

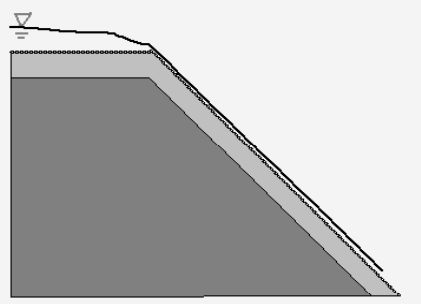

(b) Time $\mathrm{t}=2.0 \mathrm{~s}$

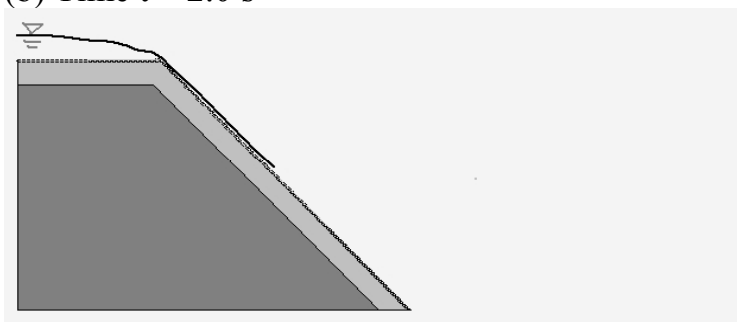

(d) Time $\mathrm{t}=4.0 \mathrm{~s}$

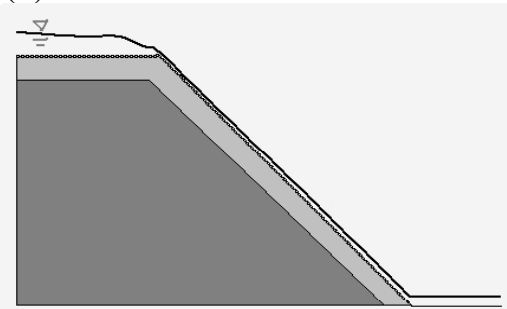

Fig. 5. Transient process of surge overflow over the RCC-strengthened levee: (a) time $t=1.0 \mathrm{~s}$ (b) $t=2.0 \mathrm{~s}$ (c) $t=3.0 \mathrm{~s}$, and (d) $t$ $=4.0 \mathrm{~s}$ for the surge height of $0.3 \mathrm{~m}$. 

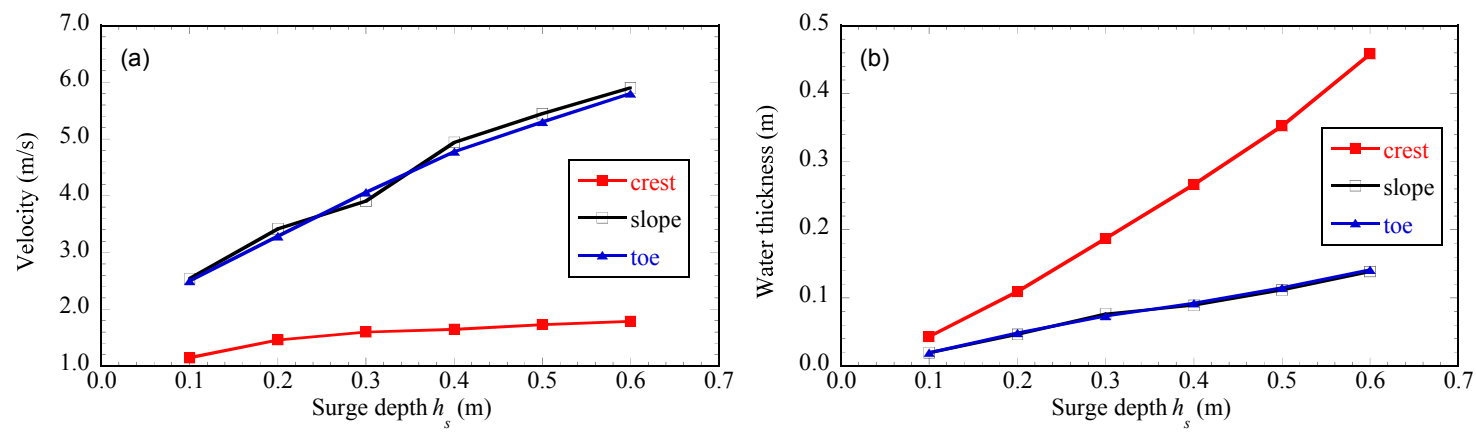

Fig. 6. Hydraulic profile at the middle of levee crest, landward-side slope, and at the toe of slope in surge overflow: (a) velocity and (b) water thickness as a function of the overflow depth. The landward-side slope is $1 \mathrm{~V}: 3 \mathrm{H}$.

\subsection{Erosion of RCC Strengthened Levee}

Erosion strength and critical shear stress are the two key parameters in the erosion model, and the selection of them is important in the model prediction. In this study, full-scale surge only overtopping hydraulic and erosion experimental data, which is available in $\mathrm{Li}$ et al. [8], are used to calibrate these parameters.

Fig. $4 \mathrm{~b}$ shows the erosion depth from the SPH model at the middle of levee crest for the surge only case as a function of time. In this case, calibrated $k_{\varepsilon}$ $=4 \times 10^{-8}, \tau_{c}=15 \mathrm{~N} / \mathrm{m}^{2}$, and a surge overflow depth $\left(h_{s}\right)$ of $0.151 \mathrm{~m}$ were obtained. As indicated in this figure, the erosion increases over time, and a bestfit curve $\left(R^{2}=0.96\right)$ was obtained. Fig. $4 c$ shows the comparison of SPH predications with the results from surge only experimental data. When time equals to $900 \mathrm{~s}$, the measured erosion is $0.057 \mathrm{~mm}$ compared to the predicted $0.053 \mathrm{~mm}$ from the calibrated SPH model (Fig. 4c).

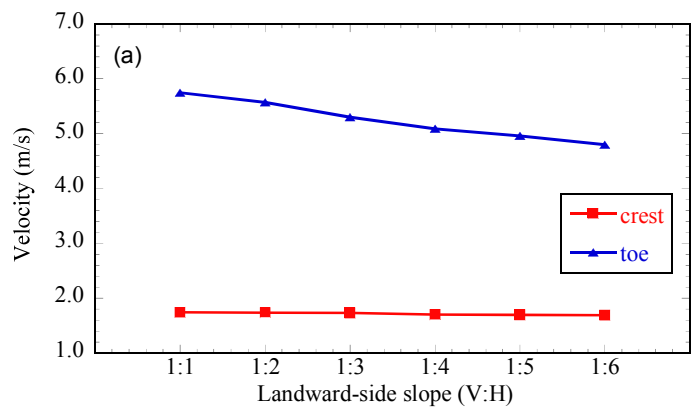

\section{Results and Discussion}

\subsection{Hydraulic Results}

Fig. 5 shows the instantaneous free surface profiles over RCC strengthened levee at different times. As the steady water overflows the levee, the critical flow transits from subcritical flow to supercritical flow along the levee crest. The flow that moves along the landward-side slope is supercritical and reaches the toe after some time.

The flow velocity and water thickness on the RCC strengthened levee for different surge depths and at three locations are shown in Fig. 6. The three locations are middle of levee crest, middle of landwardside slope and toe of landward-side slope. As shown, flow velocity increases with the surge depth. As the surge depth increases from $0.2 \mathrm{~m}$ to $0.5 \mathrm{~m}$, the flow velocity at the middle of crest increases from $1.5 \mathrm{~m} / \mathrm{s}$ to $1.7 \mathrm{~m} / \mathrm{s}$.

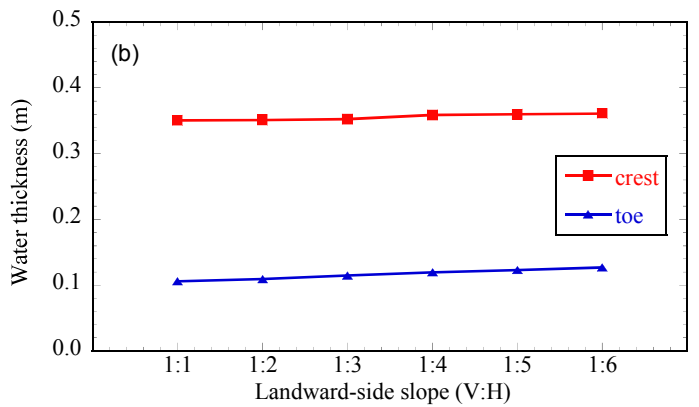

Fig. 7. Hydraulic profile at the middle of levee crest and at the toe of slope in surge overflow: (a) velocity and (b) water thickness as a function of the levee landward-side slope (V:H). The surge depth is $0.5 \mathrm{~m}$. 
The flow velocity in the slope and the toe are similar, but higher than middle of crest (Fig. 6a). When the surge depth is $0.3 \mathrm{~m}$, the flow velocity in the middle of crest, middle of slope, and the toe is 1.6 $\mathrm{m} / \mathrm{s}, 3.9 \mathrm{~m} / \mathrm{s}$ and $4.1 \mathrm{~m} / \mathrm{s}$, respectively. After flow transits from subcritical flow to supercritical flow along the levee crest, the supercritical flow moves along the landward-side slope and reaches a stable velocity after reaching the middle of landward-side slope.

Fig. $6 \mathrm{~b}$ shows the water thickness at the three locations, i.e., middle of levee crest, middle of landward-side slope and toe of landward-side slope, as a function of surge depth. The water thickness increases with surge depth, and the water thickness is higher at the crest than at the slope and at the toe. At the surge depth of $0.4 \mathrm{~m}$, the water thickness at the middle of crest is $0.27 \mathrm{~m}$, but the water thickness at the middle of slope and toe are $0.09 \mathrm{~m}$. In the supercritical flow, thinner water thickness corresponds to higher flow velocity because of the constant flow discharge over the levee.

Fig. 7 shows the flow velocity and water thickness at the middle of levee crest and at the toe as a function of the landward-side slope $(\mathrm{V}: \mathrm{H})$ for a surge depth of $0.5 \mathrm{~m}$. When the landward-side slope becomes shallower, the flow velocity at the toe decreases, but the velocity at the crest does not change significantly. For example, when the landward-side slope changes from $1 \mathrm{~V}: 3 \mathrm{H}$ to $1 \mathrm{~V}: 6 \mathrm{H}$, the flow velocity at the toe decreases from $5.3 \mathrm{~m} / \mathrm{s}$ to $4.8 \mathrm{~m} / \mathrm{s}$ while the flow velocity at the crest nearly remains at $1.7 \mathrm{~m} / \mathrm{s}$ (Fig. 7a). The change in water thickness at the toe is opposite to the flow velocity. In addition, when the landward-side slope becomes shal- lower, the water thickness increases at the toe (Fig. $7 \mathrm{~b})$.

\subsection{Erosion results}

Fig. 8a shows the erosion depth at the three locations of the RCC strengthened levee as a function of surge overflow depth. As the surge height increases, the erosion increases at these locations. The erosion depths at the slope and at the toe are always higher than those of at the crest. At the surge overflow of $0.4 \mathrm{~m}$, the erosion depth is 0.008 $\mathrm{mm}$ at the crest, $0.011 \mathrm{~mm}$ at the slope and 0.014 $\mathrm{mm}$ at the toe. But compared to the typical thickness $(300 \mathrm{~mm})$ of RCC in the levee strengthening system ( $\mathrm{Li}$ et al. 2012), the erosion depth is less than $0.005 \%$ at the toe. Therefore, the RCC strengthened levee can resist erosion damage this surge overflow for a long period.

Fig. $8 \mathrm{~b}$ shows the erosion depth as a function of flow velocity. Higher flow velocity causes more erosion on the RCC strengthened levee. For example, when the flow velocity increases from $2.5 \mathrm{~m} / \mathrm{s}$ to $5.3 \mathrm{~m} / \mathrm{s}$ at the toe, the erosion depth has a tenfold increasing.

\section{Conclusion}

This study provided a comprehensive hydraulic and erosion analysis of a levee strengthened by RCC subjected to surge only overflow condition. After comparing with full-scale overtopping experiments data, the roughness and erosion parameters are calibrated. The water thickness, flow velocity, and erosion depth are calculated. As a result of this study, the following recommendations can be made.
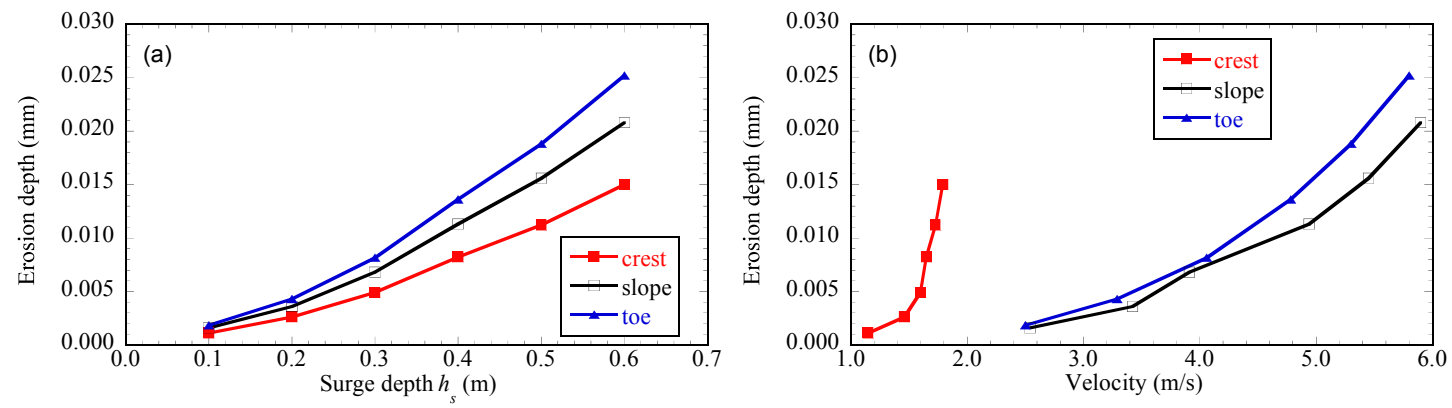

Fig. 8. Estimated erosion depth on three locations in the RCC strengthened levee as a function of: (a) surge overflow depth, and (b) flow velocity. The landward-side slope is $1 \mathrm{~V}: 3 \mathrm{H}$. 
- SPH is verified with analytical solution for the earthen levee, and the results show that SPH method can simulate free surface overflow in levee overtopping with reasonable accuracy.

- SPH results of velocity are compared with full scale overtopping tests data in the RCC strengthened levee, and the calibrated roughness $(n=0.02)$ was chosen to represent the property of RCC strengthening material. The erosion strength and the critical shear stress are calibrated after comparing with the measured erosion in the full scale overtopping tests.

- The flow velocity and water thickness increase with the surge depth. Along the slope and at the toe, the flow velocities are similar, but they are higher than that of crest. However, the water thickness is higher at the crest than at the slope and at the toe. When the landward-side slope becomes shallower, the flow velocity at the toe decreases, but the velocity at the crest does not change significantly.

- More erosion occurs at higher surge overflow, and the erosion depths at the slope and at the toe are always higher than that of at the crest. But compared with the typical thickness of RCC in the levee strengthening system, the erosion depth is nearly negligible. Thus, the RCC strengthened levee can resist erosion damage at the studied surge overflow for a long period.

- The limitation of the developed SPH model is that it is based on vertical-averaged flow velocity, which is not suitable to simulate wave overtopping or combined wave and surge overtopping conditions.

\section{Acknowledgements}

This research was funded by the Department of Homeland Security-sponsored Southeast Region Research Initiative (SERRI) at the Department of Energy's Oak Ridge National Laboratory. This support is gratefully acknowledged. The conclusions in this paper are solely those of the authors and do not necessarily reflect the opinions or policies of DHS. Endorsement by DHS is not implied and should not be assumed.

\section{References}

[1] ASCE Hurricane Katrina External Review Panel, The New Orleans Hurricane Protection System: What Went Wrong and Why? American Society of Civil Engineers, Reston, Virginia, (2007).

[2] G. L. Sills, N. D. Vroman, R. E. Wahl, and N. T. Schwanz, Overview of New Orleans Levee Failures: Lessons Learned and Their Impact on National Levee Design and Assessment. J. of Geotechnical and Geoenvironmental Eng. 134 (2008) 556-565.

[3] E. P. Perry, Innovative Methods for Levee Rehabilitation, Technical Report REMR-GT-26, U.S. Army Corps of Engineers, Waterways Experiment Station, (1998).

[4] G. J. Akkerman, P. Bernardini, J. van der Meer, H. Verheij, and A. van Hoven, Field Tests on Sea Defenses Subject to Wave Overtopping, Proc. Costal Structures, Venice, Italy, July 2-4 (2007).

[5] Y. Choi, and K. D. Hansen, RCC/Soil-cement: What's the Difference? J. of Materials in Civil Eng., 17 (2005) 371-378.

[6] F. G. McLean, and K. D. Hansen, Roller Compacted Concrete for Embankment Overtopping Protection, Geotechnical Practice in Dam Rehabilitation, L.R. Anderson, ed., Geotechnical Special Publication 35 (1993), ASCE, 188-209.

[7] G. J. Hanson, K. R. Cook, W. Hahn, and S. L. Britton, Observed Erosion Processes during Embankment Overtopping Tests. Proc., 2003 ASAE Annual Int. Meeting, ASABE, Las Vegas, Paper No. 032066 (2003).

[8] L. Li, Y. Pan, C.P. Kuang, and F. Amini, Full Scale Laboratory Study of Combined Wave and Surge Overtopping of a Levee with RCC Strengthening System, Ocean Eng., 54 (2012) 70-86.

[9] J.J. Monaghan, Simulating Free Surface Flows with SPH. Journal of Computational Physics, 110 (1994) 399-406.

[10] J.J. Monaghan, and A. Kos, Solitary Waves on a Cretan Beach. J. of Waterway, Port, Coastal, and Ocean Eng., 125 (1999) 145-154.

[11] P. Liu, P.Z. Lin, K.A. Chang, and T. Sakakiyama, Numerical Modeling of Wave In- 
teraction with Porous Structures. J. of Waterway, Port, Coastal, and Ocean Eng,, 125 (1999) 322-330.

[12] T. Li, P. Troch, and J. De Rouck, Wave Overtopping over a Sea Dike. J. of Computational Physics, 198 (2004) 686-726.

[13] R. Ata, and A. Soulaimani, A Stabilized SPH Method for Inviscid Shallow Water Flows. International J. for Numerical Methods in Fluids, 47 (2005) 139-159.

[14] S. Shao, C. Ji, D. I. Graham, D. E. Reeve, P. W. James, and A. J. Chadwick, Simulation of Wave Overtopping by an Incompressible SPH Model. Coastal Eng., 53 (2006) 723-735.

[15] X. Rao, L. Li, F. Amini, and H. Tang, SPH Modeling of Combined Wave and Surge Overtopping and Hydraulic Erosion of $A C B$ Strengthened Levee System. J. of Coastal Research, doi: http://dx.doi.org/10.2112/JCOAST RES-D-11-00220.1 (2012).

[16] J. J. Monaghan, SPH Compressible Turbulence. Monthly Notices of the Royal Astronomical Society, 335 (2002) 843-852.
[17] J. J. Monaghan, SPH Simulations of Shear Flow. Monthly Notices of the Royal Astronomical Society, 365 (2006) 199-213.

[18] A. Khayyer, H. Gotoh, and S. Shao, Corrected Incompressible SPH Method for Accurate Water-Surface Tracking in Breaking Waves. Coastal Eng., 55 (2008) 236-250.

[19] R. A. Dalrymple, and B.D. Rogers, Numerical Modeling of Water Waves with the SPH method. Coastal Eng., 53 (2006) 141-147.

[20] J. J. Monaghan, Smoothed Particle Hydrodynamics. Annual Review of Astronomy and Astrophysics, 30 (1992) 543-548.

[21] P. Kristof, B. Benes, J. Krivanek, and O. Stava, Hydraulic Erosion using Smoothed Particle Hydrodynamics. Eurographics, 28 (2009) 236-250.

[22] M. B. Liu, G. R. Liu, and K. Y. Lam, Investigations into Water Mitigations using a Meshless Particle Method, Shock Waves, 12 (2002) 181-195.

[23] F. M. Henderson, Open Channel Flow. New York, Macmillan Publishing Co., Inc., (1966). 